\title{
Práticas pedagógicas em terreiros de quimbanda: escritas sobre educação de crianças e infâncias
}

\author{
Pedagogical practices in the terraces of quimbanda: written about education \\ of children and childhood
}

Rodrigo Lemos Soares

Universidade Federal de Pelotas - Faculdade de Educação -Programa de Pós-Graduação em Educação - Doutorado - Grupo Interdisciplinar de Pesquisa: Narrativas, Arte, Linguagem e Subjetividade (GIPNALS). rodrigosoaresfurg@gmail.com

Denise Marcos Bussoletti Universidade Federal de Pelotas - Faculdade de Educação - Programa de Pós-Graduação em Educação - Doutorado - Coordenadora do grupo Interdisciplinar de Pesquisa: Narrativas, Arte, Linguagem e Subjetividade (GIPNALS). denisebussoletti@gmail.com

Resumo: As práticas pedagógicas em terreiros de Quimbanda indicam os modos, pelos quais, os sujeitos, são ensinados nesses locais. Este texto apresenta algumas ações educativas com a atenção voltada às crianças e infâncias de seis terreiros de Quimbanda de Rio Grande, no interior do Rio Grande do Sul. O estudo que segue possui caráter narrativo, escrito, a partir de excertos de diários de campo, produzidos em seis terreiros, segundo os quais as práticas pedagógicas são da ordem da liberdade de escolha, veiculadas por meio das brincadeiras e das rotinas de cada local. Também, percebeu-se que em relação às crianças, elas são compreendidas como parte dos terreiros e por meio dos rituais elas são pedagogizadas. Além disso, elas possuem livre circulação nos terreiros sendo responsabilidades dos adultos mediar situações e orientar a verbalização de saberes, sem que isso as impossibilite de expressarem seus pensamentos.

Palavras-chave: Educação. Práticas pedagógicas. Terreiros. Crianças. Infâncias.

Abstract: Pedagogical practices in the terraces of Quimbanda indicate the modes, for which, the subjects, are taught in these locations. This text presents some educational activities with attention devoted to children and childhoods of six terreiros de Quimbanda of Rio Grande, within the Rio Grande do Sul. The study that follows has written narrative character, from excerpts of diaries, produced in six terraces, that pedagogical practices are of the order of freedom of choice, broadcast through the jokes and routines of each location. Also, it was noticed that in relation to children, they are understood as part of the terraces and the rituals they are educated. In addition, they have free movement on the terraces being responsibilities of adults mediate situations and guide the verbalization of knowledge, without that would express your thoughts.

Key-words: Education. Pedagogical practices. Terraces. Kids. Childhoods. 


\section{Assentando o terreno...}

Pensar a Educação em Terreiros ${ }^{1}$ parte da premissa de que nestes locais ocorrem modos de educar que forjam subjetividades, por meio de suas ações ritualísticas. Nesse sentido, as práticas pedagógicas, nos terreiros de Quimbanda², podem ser visualizadas em diferentes momentos das rotinas destes lugares. Tal afirmativa parte das análises produzidas ao longo de um ano de observações em seis terreiros de Quimbanda, localizados no município de Rio Grande, interior do Rio Grande do Sul (SOARES; DILLMANN, 2020). Destaco alguns dos acontecimentos e como as pedagogias são desenvolvidas, observando especificamente os tratos com as crianças que frequentaram os terreiros, ao longo da produção de dados que, por sua vez, foram transcritos em um arquivo de pesquisa, a partir de entrevistas semi-estruturadas (GIL, 1999) e analisados, a partir da formação de um total de três categorias: 1. Crianças e infâncias nos terreiros; 2. Saberes ritualísticos e práticas pedagógicas e 3. Os saberes e fazeres dos terreiros. Para este texto, abordo apenas a primeira, por meio da investigação narrativa (CONNELLY; CLANDININ, 1995).

Dito isso, destaco que a escrita deste artigo está pautada na noção de sujeito, poder e discurso propostos por Foucault (1999, p. 32), quando o autor afirma que "[...] enquanto o sujeito humano é colocado em relações de produção e de significação, é igualmente colocado em relações de poder muito complexas". Esta opção ético-estética, depõem no sentido da possibilidade de que tais conceitos permitem-me atentar ao foco de práticas pedagógicas nos terreiros que são da ordem das culturas (CANCLINI, 2006), dos saberes populares. Logo, as pedagogias dos terreiros produzem significados, posições de sujeitos, ordenando contextos e forjando subjetividades, auxiliando-me na definição contingencial e contextual, deste texto.

Especificadas as orientações iniciais do trabalho, reitero que as proposições e recortes narrativos (CONNELLY; CLANDININ, 1995) expostos no artigo resultam de olhares (VEIGANETO, 2002) aos relatos de uma mãe de santo $^{3}$ e um pai de santo, dirigentes de terreiros de Quimbanda, situados em diferentes bairros do município de Rio Grande/ RS. Os(As) participantes desse estudo são: Dione da Maria Padilha e José Carlos do Maioral. Os nomes foram indicados e autorizados, em documento de termo de assentimento e aceite de participação da pesquisa, por eles(as). Os destaques em itálico indicam quais entidades, exus e pombagiras ${ }^{4}$, que representam seus terreiros. Foram realizadas visitas para observações, uma em cada terreiro, as 
quais ocorreram, respectivamente nos dias: 23, 24 e 27 de janeiro e 14, 16 e 19 de fevereiro, no ano de 2020.

A partir de suas narrativas constituí um aparato conceitual que foi orientado pela percepção de usos da linguagem em sua função de produção e intercâmbio de significados, a partir de saberes populares (CASCUDO, 2012) por vezes sujeitados (FOUCAULT, 2005), e que são oriundos de pedagogias culturais (STEINBERG; KINCHELOE, 2001). Com relação aos estudos sobre crianças e infâncias o aporte teórico está embasado em Barbosa, Delgado e Tomáz (2006), Nunes (2015), Sarmento (2013) e Pinto e Sarmento (1997). Incitado pelas narrativas acerca da pedagogizações que, geralmente, não entram na ordem discursiva (FOUCAULT, 2000).

\section{Crianças e Infâncias nas rotinas dos terreiros...}

"[...] As crianças são a alma do terreiro, elas precisam circular livremente, porque, esse lugar é delas, a existência do terreiro depende da presença delas [...]” (Dione da Maria Padilha - 23 de fevereiro de 2020). Ao compor este cenário indico, inicialmente, algumas condições de possibilidade para entender os conceitos de infâncias e crianças, para a participante. Recorro a Pinto e Sarmento (1997) ao expressarem que:

[...] crianças existiram desde sempre, desde o primeiro ser humano, e a infância como construção social existe desde os séculos XVII e XVIII. Nada poderia, por consequência, explicar esta atenção recente em todo o mundo - a atual visibilidade do fenômeno social da infância, não fora o fato dos tempos atuais introduzirem novas circunstâncias e condições à vida das crianças e à inserção social da infância (PINTO; SARMENTO, 1997, p. 09 - 10).

Essas condições expostas pelos autores, são, de fato, propulsoras para pensar as infâncias e, por sua vez, as crianças, os terreiros. Nestes espaços, elas são parte integrante do conjunto social, suas vozes são consideradas, ainda que a elas - as crianças, alguns ritos sejam "proibidos". Contudo, conforme narrado por Dione o acesso às práticas, fala e vivências possuem um amplo espectro de deslocamento, pois, da presença das crianças dependem a existência dos terreiros. Para tanto, dialogo com as autoras, Barbosa, Delgado e Tomás (2016, p. 105) ao escreverem que "[...] em alguns contextos socioculturais, os rituais de transição são bem definidos e a infância geralmente termina no momento biológico de mutação do corpo", contudo, ainda que os rituais sejam, também, demarcadores de transição, eles extrapolam a necessidade de caracterizar os sujeitos, separando-os(as) em crianças e adultos(as). Ainda que, como as autoras discorrem no texto, exista uma gama de intencionalidades para separação, aparentemente, a que possua mais 
relevância, seja a compreensão de que são diferentes e que, por isso, serem observados(as) de lugares outros e não menorizados(as) “[...] a criança não é o adulto imperfeito e imaturo, mas é o Outro do adulto, isto é, entre a criança e o adulto há uma relação de não incompletude, mas de alteridade" (SARMENTO, 2013, p. 19).

Nesse caso, às práticas pedagógicas definem-se pela experimentação e ampla liberdade de circulação, das crianças dentro dos terreiros, as aprendizagens são da ordem da vivência. As crianças, ainda que sejam "privadas" de algumas rotinas ritualísticas, em sua maior parte são educadas, pelos ritos e rituais, dependendo dos preceitos de cada terreiro. Desse modo,

[...] ser criança varia entre sociedades, culturas e comunidades, pode variar no interior da frataria de uma mesma família e varia de acordo com a estratificação social. [...] varia com a duração histórica e com a definição institucional da infância dominante em cada época (PINTO; SARMENTO, 1997, p. 12).

Tal como escrito por Pinto e Sarmento (1997), estou me referindo às experiências específicas dentro dos terreiros, logo, não tenho a pretensão de generalizar o saber de que as práticas sejam globalizantes e, assim, compreendidas e difundidas, de igual modo, em todos os espaços. Porém, busco "[...] combater a ideia da não racionalidade das crianças perspectivando a infância como uma categoria social específica, mas não isolada e separada de todo social" (BARBOSA, DELGADO, TOMÁS, 2016, p. 114). Para tanto, ao falar das crianças descrevo-as como "[...] ser biopsicossocial e a infância como categoria estrutural da sociedade" (SARMENTO, 2013, p. 15).

[...] A presença das crianças modifica a rotina de um terreiro, porque elas são distintas, umas vem e choram outras chegam aqui e se divertem, como se fosse uma parquinho. Nossa função é mediar as presenças delas aqui e com isso ir ensinando a elas o que é permitido e o que não é, aqui dentro pelo menos. Daí a gente ensina quais são as rotinas da casa, elas aprendem tudo e compreendem que o terreiro também é delas (Dione da Maria Padilha - 24 de janeiro de 2020).

Segundo a participante são percebidas diferenciações entre as crianças. Nessa lógica, compete a eles(as) (mães e pais de santo) orientarem às ações das crianças ao adentrarem nos terreiros. Ao agirem assim, tornam possível o espaço de ensino e aprendizagem dentro desses locais. Dito isso, exponho a compreensão de que infâncias e crianças são conceitos a serem operados, no plural, pois, são definidos pelos múltiplos vetores socioculturais, não esquecendo da compreensão da existência das culturas da infâncias, as quais, não são fixas (SARMENTO, 2013; STEINBERG; KINCHELOE, 2001). Assim, compreendo que: 
O desafio contemporâneo consiste precisamente em afirmar o campo dos Estudos da Criança, como uma área científica não apenas legítima, mas influente na produção do conhecimento sobre as crianças e, por consequência, fundante de uma renovada reflexividade institucional sobre a infância, com incidência nas políticas públicas, e, entre elas, nas políticas educativas, na formação de professores e na fundamentação da intencionalidade educativa nas escolas e nas creches (SARMENTO, 2013, p.14).

Ou, para além, do exposto por Sarmento (2013), os saberes em torno dos conceitos de infâncias e crianças atingem todos os campos da esfera social, uma vez que, cada vez mais, elas possuem "livre" acesso, ainda que silenciadas, na maior parte dos momentos. Por isso, estas discussões perpassam uma noção de que tanto as metodologias de pesquisas, quanto as epistemologias, pela filosofia da linguagem, principalmente, exigem uma questão de interdisciplinaridade, para que se possa, minimamente, compreender estes sujeitos outros, suas necessidades, a partir de si, ao invés, de um olhar adultocêntrico. Isso porque, “[...] o que é comum nas crianças é diferentemente vivido por elas em função de sua diversidade [...] Sem atenção à diversidade, a análise da categoria geracional fica confinada às crianças dentro da normatividade dominante" (SARMENTO, 2013, pp. 30 - 31).

É no campo, da interdisciplinaridade e, acima de tudo, da diversidade que estes conceitos precisam ser lidos. Para que não pareça uma receita, reitero o contingenciamento desse estudo, em terreiros onde as crianças e as infâncias dialogam e interagem com mundos diferentes, sem que para isso, estejam alijadas dos seus. O cotidiano dos terreiros abrange e propicia espaçostempos, nos quais as crianças possam se sentir como tal e, ainda assim, realizarem as tarefas pertinentes aos espaços religiosos. A centralidade do terreiro não está nos modos de vida, mas sim, nas condições de possibilidade para que crianças e infâncias percebam-se parte constituinte dele e não como objeto de complementação das práticas ritualísticas. Nessa esteira apresento a narrativa de Dione da Maria Padilha, ao dizer que: "[...] Aqui no terreiro as crianças devem falar, gritar, correr, brincar, enfim, expressarem seus sentimentos, questionarem, terem espaço e liberdade para escolber o que e como querem aprender [...]" (Dione da Maria Padilha - 27 de janeiro de 2020). Segundo a mãe de santo, as possibilidades de movência e agenciamento das crianças estão orientados pelas liberdades em suas ações. Desse modo, 
[...] As crianças desenvolvem-se como seres sociais no quadro das possibilidades delimitadas pela regulação social da infância [...] as culturas infantis são profundamente interativas: estar com os outros, partilhar experiências e saberes, comunicar para além de tudo o que separa é uma condição central da afirmação das crianças como sujeitos. A construção dos mundos de vida das crianças, a possibilidade de sua subjetivação e autonomia é fortemente dependente da possibilidade de o processo socializador ocorrer fora da orientação para o individualismo (SARMENTO, 2013, pp. 39 - 41).

Ainda que possa observar aproximações entre o mencionado por Dione da Maria Padilha e Sarmento (2013, p. 42) julgo necessário que sejam possibilitadas práticas pedagógicas que conduzam "[...] uma ação educativa promotora de uma subjetivação autêntica e uma autonomia real das crianças". Sentar à altura delas, escutá-las e junto delas, difundir suas ideias são ações inerentes para uma educação incentivadora das liberdades de expressão, produção dos seus espaços-tempos e cientes dos saberes que desejam aprender, lembrando que um saber "[...] se define por possibilidades de utilização e de apropriação oferecidas pelo discurso" (FOUCAULT, 2013, p. 220). Assim, as crianças dos terreiros estudados interagem com os saberes que lhes convém quando estão circulando entre as rotinas dos terreiros, propondo possibilidades e soluções às problemáticas que por ventura apareçam. Isso porque, são elas (as crianças) que precisam apresentar respostas para situações às quais se envolvem, desde que não estejam em risco.

"[...] As crianças aqui da casa são ensinadas junto dos adultos, por isso, a gente precisa ser comedido, não pode sir falando tudo e de tudo. É difícil estabelecermos um jeito só de ensinar, porque elas trazem muitas coisas de casa, e também, elas vivem o terreiro, sempre" (José Carlos do Maioral - 14 de fevereiro de 2020). Para o participante não existe, em princípio, algum tipo de separação entre crianças e adultos, porém, ele destaca que existem momentos só delas. Mas, afirma que é difícil ter apenas um modo para ensinar, pois elas possuem suas experiências que são do campo privado, do seio de suas famílias. Nesse sentido, compartilho da ideia exposta no estudo de Nunes (2015, p. 599) ao escrever que "[...] a necessidade de contemplar a existência de diferentes infâncias decorre de um sentimento pessoal, profissional, investigativo, curioso, atento com que tenho observado as possibilidades em pluralizá-las e, por isso, a dificuldade em interpretá-las. Traduzo essa narrativa, para pensar os campos da pesquisa, de modo, a tentar contemplar, em grande escala, problemas que não são, como nos fazem pensar, transversais, mas sim, estruturais de uma sociedade que ainda, nega e invisibiliza a existência de educação infantil nos terreiros, além disso, desconsidera os saberes (CASCUDO, 2012) desses locais. 
Para José Carlos do Maioral as crianças em seu terreiro (16 de fevereiro de 2020) "[...] elas são capazes de nos condurir a outras realidades, nos mostram o mundo pelos olhos delas e assim nós aprendemos. Nós ensinamos é como elas precisam saber do que estão falando, um meio de campo, sabe?”. Segundo o pai de santo as crianças, que frequentam o seu terreiro propiciam visões de mundo, a partir dos seus referenciais. A função pedagógica dentro da sua casa religiosa está em mediar o que as crianças falam, não no sentido de barrar suas narrativas, mas diferente disso, fazer com elas percebam o que estão falando. Nessa lógica considero que,

[...] as crianças, para Benjamin, falam não só do seu mundo e da sua ótica; falam também do mundo adulto, da sociedade contemporânea. Imbuir-se desse olhar infantil crítico é aprender com as crianças e não se deixar infantilizar. Conhecer a infância passa a significar uma das possibilidades para que o ser humano continue sendo sujeito crítico da história que o produz (KRAMER, 2002, p. 46).

Segundo a autora, as crianças modificam as situações forjadas apenas nos olhares do adultos, logo, precisamos cuidar para não infantilizarmos nossas práticas pedagógicas, a fim de mantermos diálogo conciso e coerente com as percepções de mundo delas. Nessa lógica, precisamos ter em vista que ao propormos um estudo com referencial que entenda a infância, enquanto categoria social, sujeitos históricos, produtores(as) de culturas, “[...] a ideia central é a de que as crianças são autoras, mas sabemos que precisam de cuidado e atenção” (KRAMER, 2002, p. 42). Narrativa que aproximo da ideia de mediação de saberes exposta por Dione da Maria Padilha. Nessa mesma esteira destaco que

[...] aqui as crianças aprendem pela prática, elas são convidadas a observar os rituais e depois a fazer, óbvio que não deixamos elas mexerem com faca, até porque, ainda não é o momento para isso. Tudo é um convite à brincadeira, este é o caminho que nós usamos para ensinar aqui. Elas aprendem porque as coisas ensinadas são praticadas, tudo usa o corpo, porque nos terreiros é assim que tu é ensinado. Tudo dividido, com seu tempo, cada rito tem sua hora de ser ensinado. Nós deixamos elas livres para brincar e nas brincadeiras colocamos o que elas precisam aprender, por exemplo, as danças, os toques de tambor, os jogos, as coisas de cozinha, isso para todos guris e gurias (José Carlos do Maioral - 19 de fevereiro de 2020).

Para o pai de santo os ensinamentos são propostos por meio das experiências práticas. $\mathrm{O}$ aprendizado parte de convites, primeira a observação e depois ao fazer, com os cuidados necessários para manutenção da integridade das crianças. Tudo que é ensinamento é exposto na prática, também, logo, segundo ele, os aprendizados passam pelos corpos. Além disso, menciona que os saberes possuem tempo e hora, porém, as crianças circulam livremente, momentos nos 
quais são propostos os ensinamentos necessários às rotinas dos terreiros. Outro destaque do participante é que esses processos de ensino são iguais para meninos e meninas.

Esses dados nos aponta para ideia de há “[...] uma diversidade de experiências culturais de ensino e aprendizagem” (COHN, 2005, p. 37). As crianças, nessa pesquisa, aprendem sobre às dinâmicas dos terreiros, por meio das liberdades de escolha, pautada nas brincadeiras, conforme observado no estudo de Caputo (2012). Sobre a aprendizagem passar pelos corpos Rabelo e Santos (2011, p. 190) já sinalizam essas possibilidades, para elas, aprender nos terreiros “[...] não é primeiramente adquirir um domínio intelectual do que se passa, é ajustar-se à cena, ser capaz de responder corporalmente a seu apelo e, desta forma, tornar-se parte dela. É um processo em que sensibilidades são despertadas, desenvolvidas e canalizadas". Contudo, as práticas pedagógicas são oportunizadas em etapas, como salientou o participante, logo, aprender nos terreiros implica em estar presente, oportunizar-se as experimentações das práticas, colocar-se em contato com os saberes das casas (FALCÃO, 2010). Ainda que tenham momentos certos, isso não implica em ordem cronológica, nessa lógica é possível encontrar crianças que saibam mais das práticas ritualísticas do que adultos, fator que pode ser observado no estudo de Falcão (2010).

Por fim, reiteramos a questão do brincar com relação às práticas pedagógicas, segundo as observações e narrativas dos(as) participantes às pedagogias dos terreiros (FALCÃO, 2010) estão pautadas pelo viés do simbólico, aquele que diz algo às crianças e, por isso, elas vão ao seu encontro. "[...] Esta articulação permite às crianças apropriarem-se de aspectos da cultura dos adultos que depois usam, refinam e expandem. [...] As crianças alargam a cultura de pares e contribuem para reprodução do mundo adulto” (CORSARO, 2002, pp. 118-119).

\section{Práticas pedagógicas: desenhando contextos religiosos...}

As narrativas, acerca das práticas pedagógicas estão imbricadas nas formas como percebo as atividades ritualísticas e organizações dos terreiros que participaram dessa pesquisa. Ainda que, com alguns diferenciações, foram visíveis alguns modos de correlação, seja no campo social, ritualístico e, também, nos modos de tratar e conceber as crianças (CAPUTO, 2012). Destaco, que as pedagogizações são do campo das liberdades, estas vivenciadas pelas crianças dos terreiros indicando-nos noções de autonomia presentes nos diferentes locais visitados. A educação das crianças pelos fazeres ritualísticos, apresentam diferenciações, contudo, sob um ponto de vista estrutural, de pensamentos, alguns itens são reiterados e, por vezes, consolidados, ainda que, em contextos distintos. 
Pesquisar as ações pedagógicas dos terreiros observando suas direcionalidades às crianças colocou-me de frente com a temática, isso porque, “[...] o que se encontra no começo da história não é a identidade [...] é a discórdia entre as coisas, é o disparate” (FOUCAULT, 2004, p. 18). Afirmo este posicionamento por ser membro de um centro religioso e perceber que alguns fundamentos distoam dos saberes que possuo, os quais me forjam como religioso, Quimbandeiro. Foram as inquietações com as coisas que já sabia que me impulsionaram a este escrito com muitas referências, as quais forjam o "[...] ritual da escrita dialoga com os ritos da academia, mas, também, com os processos cotidianos de ganhos e/ ou "perdas" que o (a) autor(a) acessa para conceber a escrita um tom de humanidade e vida que muitos textos nem sempre conseguem imprimir" (NUNES, 2015, p. 611).

Consideramos que as pedagogias dos terreiros (FALCÃO, 2010; CONCEIÇÃO, 2006), nesse estudo, implicam na produção de sujeitos religiosos, ao mesmo tempo em que históricos, que se percebam como utilizadores e produtores de culturas (STEINBERG, 1997), mais que isso, estabelecem saberes e fazeres. Uma noção de saberes embasada em Foucault (2013, p. 219) quando "um saber é aquilo de que podemos falar em uma prática discursiva que se encontra assim especificada: o domínio constituído pelos diferentes objetos que irão adquirir ou não um status científico". Escrever este texto orientou-nos no sentido de pensarmos as narrativas que foram proferidas “[...] atrás da verdade sempre recente, avara e comedida [...]" (FOUCAULT, 2004, p.19) sob a qual, “[...] existe a proliferação milenar dos erros” (idem). Dito isso, fomos conduzidos pelos caminhos de outros saberes, outras pedagogias, educações que partem da socialização por espaços em que os sujeitos assumem a posição para falar dos objetos de que se ocupam seus discursos.

1 Terreiros, casa de santo ou casas de religião, são os locais onde praticantes das religiões de matriz africana desenvolvem seus cultos e rituais (CAPUTO, 2012).

2 Quimbanda é uma vertente das religiões de matriz africana praticadas no Brasil. Ela pode ser evidenciada como um complemento à Umbanda (outra vertente do africanismo, porém, com discussões acerca de sua naturalidade brasileira), agindo ambas, enquanto complementares. Outro ponto a ser destacado é sua evidenciação ao povo da rua, nomenclatura dirigida às entidades que compõem os panteões de exus, pombagiras, povo do oriente, povo cigano. Além disso, nota-se sua prática com rituais de imolação, sacralização, dentre outras ações que instituem suas especificidades religiosas (SOARES, 2018).

${ }^{3}$ Mães e Pais de santo são as sacerdotisas e os sacerdotes que orientam os(as) fieis, com relação às práticas religiosas. Elas(es) são responsáveis pela formação e condução espiritual dos(as) frequentadores(as) dos terreiros (SOARES, 2018).

${ }^{4}$ Exus e Pombagiras são as entidades representativas da Quimbanda. Eles simbolizam a energia espiritual que rege um(a) médium. Na mitologia, eles(as) podem ser compreendidos(as) como seres condutores das mensagens entre os orixás, no entanto, para alguns estudiosos(as), eles(as) também são deuses(as). Uma de suas características é serem muito semelhantes aos humanos e, por isso, ocorrem muitos folclorismos (CASCUDO, 2012) com relação 
a estas entidades, além de certa diminuição de suas qualidades, por serem algumas vezes identificados(as) como malfeitores(as) (SOARES, 2018).

\section{Referências}

BARBOSA, M. C.; DELGADO, A. S.; TOMAS, C. Estudos da Infância, Estudos da Criança: Quais Campos? Quais Teorias? Quais Questões? Quais Métodos? Interação, UFG, 2016.

CANCLINI, N. G. Culturas híbridas. São Paulo: Edusp, 2006.

CAPUTO, S. G. Educação nos terreiros: e como a escola se relaciona com crianças de candomblé/ Stela Guedes Caputo. - 1. Ed. - Rio de Janeiro: Pallas, 2012.

CASCUDO L. da C. Dicionário do Folclore Brasileiro - Edição Revista, Atualizada e Ilustrada. 12a ed. São Paulo: Global, 2012.

COHN, C. Antropologia da criança. Rio de Janeiro: Jorge Zahar, 2005.

CONCEIÇÃO, L. A. A. da. A Pedagogia do Candomblé: aprendizagens, ritos e conflitos.

Dissertação (Mestrado em Educação) - Departamento de Educação. Universidade do Estado da Bahia. Salvador: 2006.

CONNELLY, M.; CLANDININ, J. Relatos de Experiência e Investigação Narrativa. In:

LARROSA, J. B. Déjame que te Cuente. Barcelona: EDITORIAL LAERTES, 1995.

CORSARO, W. A. A reprodução interpretativa no brincar ao "faz-de-conta" das crianças.

Educação, Sociedades \& Culturas, Porto, n. 17, p. 113-134. 2002.

FALCÃO, C. R. Ele já nasceu feito: o lugar da criança no Candomblé. Dissertação de Mestrado em Antropologia pela Universidade Federal de Pernambuco. Recife: 2010.

FOUCAULT, M. A Ordem do Discurso: aula inaugural no Cóllege de France, pronunciada em 2 de dezembro de 1970/ Michel Foucault; [Trad.] SAMPAIO, L. F. de A. 23 ed. São Paulo: Loyola, 2013.

FOUCAULT, M. Em defesa da Sociedade: curso no Collége de France. [Trad.] GALVÃO, M. E. A. P. São Paulo: WMF Martins Fontes, 2005.

FOUCAULT, M. Nietzsche a genealogia e a História. In. Microfísica do poder. [Trad.] MACHADO, R. Rio de Janeiro: Graal, 2004.

FOUCAULT, M. Sobre as maneiras de escrever história: entrevista a R. Bellour. In: MOTTA, M. da [Org.]. Ditos e escritos II: arqueologia das ciências e história dos sistemas de pensamento. 1. ed. Rio de Janeiro: Forense. p. 62-77. 2000.

FOUCAULT, M. As palavras e as coisas: uma arqueologia das ciências humanas / Michel Foucault; [Trad.] MUCHAIL, S. T. — 8 a ed. — São Paulo: Martins Fontes, 1999. 
GIL, A. C. Métodos e técnicas de pesquisa social. 5 ed. São Paulo: Atlas, p. 128-138. 1999.

KRAMER, S. Autoria e autorização: questões Éticas na pesquisa com crianças. Cadernos de Pesquisa, n. 116, p. 41-59, julho/ 2002.

NUNES, G. H. L. A construção social da infância nas políticas públicas, nos discursos científicos e nas práticas sociais. Revista eletrônica de Educação, vol. 9, nº 2, p. 597 -614, 2015.

RABELO, M. C.; SANTOS, R. M. B. Notas sobre o aprendizado no Candomblé. Revista FAEEBA, Salvador, v. 20, n. 35, p. 187-200, 2011.

SARMENTO, M. J.; PINTO, M. As crianças e a infância: definindo conceitos, delimitando o campo. In: SARMENTO, M. J; PINTO, M. [Org.]. As crianças contexto e identidades. Braga: Universidade do Minho, 1997. p. 09 - 30

SARMENTO, M. J. A sociologia da infância e a sociedade contemporânea: desafios conceituais e praxeológicos. In: ENS, R.; GARANHANI, M. [Org.]. Sociologia da infância e a formação de professores. Curitiba: Champagnat, p.13 - 46, 2013.

SOARES, R. L.; DILLMANN, M. Narrativas históricas: ensaiando movimentações de exus e pombagiras em terreiros de Quimbanda de Rio Grande/ RS. Educação (UFSM), Santa Maria, p. e27/ 1-18, mar. 2020.

SOARES, R. L. "Quero ver balanciar!” o ensino de danças de exus e pombagiras em terreiros de Quimbanda do Rio Grande/RS. Dissertação (mestrado) - Universidade Federal do Rio Grande, Programa de PósGraduação em História, Rio Grande/RS, 2018.

STEINBERG, S. Kindercultura: a construção da infância pelas grandes corporações. In: SILVA, L. H. da; AZEVEDO, J. C. de; SANTOS, E. S. dos. [Orgs.]. Identidade social e construção do conhecimento. Porto Alegre, PMPA, 1997.

STEINBERG, S.; KINCHELOE, J. [Orgs.] Cultura infantil: a construção corporativa da infância. Rio de Janeiro: Ed. Civilização Brasileira, 2001.

VEIGA - NETO, A. Olhares... In: COSTA, M. V. [Org.]. Caminhos Investigativos: novos olhares na pesquisa em Educação. 2 ed. Rio de Janeiro: DP\&A, 2002. p. 23-38.

Recebido em: 18 fev. 2019 / Aprovado em: 27 fev. 2020

Cite como (ABNT NBR 6023:2018)

SOARES, Rodrigo Lemos; BUSSOLETTI, Denise Marcos. Praticas Pedagógicas em terreiros de Quimbanda: escritas sobre educação de crianças e infâncias. Dialogia, São Paulo, n. 34, p. 233-243, jan./abr. 2020. Disponível em: https://doi.org/10.5585/Dialogia.N34.11648. 